\title{
El turismo rural: posible promotor en la rehabilitación sostenible de la arquitectura popular
}

\section{PAZ NÚÑEZ MARTÍ}

> Universidad de Alcalá, Madrid, España.paz.nunhez@uah.es

Universidad de Valparaíso

Facultad de Arquitectura

Revista Márgenes

Espacio Arte Sociedad

El turismo rural: posible promotor en la rehabilitación

sostenible de la arquitectura popular

Septiembre 2015 Vol. 12 № 16

Páginas 34 a 44

ISSN elec. 0719-4463

ISSN imp. 0718-4034

Recepción: Agosto 2015

Aceptación: Noviembre 2015

\section{RESUMEN}

El objetivo del artículo es estudiar el papel del turismo rural en la recuperación de la arquitectura popular, preguntándonos sobre las características y sostenibilidad de esta relación tomando a España como caso de estudio. Aunque comienza más tarde que en el norte europeo, el turismo rural se ha consolidado como una de los paradigmas más pujantes en la península ibérica. $Y$ al igual que sucedió con el turismo cultural respecto a la recuperación de los centros históricos, el turismo rural se presenta como una oportunidad para revertir la decadencia económica, el despoblamiento del territorio y para dar a conocer y/o recuperar el patrimonio vernáculo; esas obras anónimas que recogen una tradición constructiva, un saber común conformado e integrado en el entorno, que ahora están siendo recuperadas para usos turísticos. Sin embargo, los resultados de estas intervenciones son disímiles. Existen ejemplos que permitieron una recuperación integral y sostenible del patrimonio de una región. Mientras otras responden más al imaginario del viajero y a la rentabilidad económica que al respeto por el patrimonio, bien por desconocimiento de usos y técnicas tradicionales o por la pérdida de la memoria histórica. Frente a situación, proponemos estudiar la viabilidad de otras estrategias de intervención que no sean únicamente las del turismo "prepotente", evitando las radicales transformaciones sociales, urbanas y paisajísticas que suele imponer.

PALABRAS CLAVE

turismo, arquitectura folclórica, patrimonio vernacular, sustantibilidad rural, pastoreo

\section{Rural tourism: possible promoter in the sustainable rehabilitation of popular architecture \\ ABSTRACT}

The article aims to study the role of rural tourism in the recovery of popular architecture, wondering on the characteristics and sustainability of this relationship and taking Spain as a case study. Although it begins later than in northern Europe, rural tourism has become one of the most strongest paradigms in the Iberian peninsula. And just as it happened with the cultural tourism with respect to the recovery of the historical centres, rural tourism appears as an opportunity to reverse the economic decline, the depopulation of the territory and to give to publicize and/or recover the vernacular heritage; these anonymous works that shows a constructive tradition, a common knowledge formed and integrated into the environment, which are now being recovered for tourist purposes. However, the results of these interventions are dissimilar. There are examples which allowed a comprehensive and sustainable recovery of the heritage of a region. While others respond more to the imagery of the traveller and economic returns that to the respect for the heritage, either through ignorance of uses and traditional techniques or by the loss of historical memory. Before it, we propose to study the viability of other strategies of intervention that are not only those of the "arrogant" tourism, avoiding the radical social, urban and landscape transformations often impose.

KEYWORDS

tourism, folk architecture, vernacular heritage, rural sustainability, shepherding 


\section{TURISMO Y PATRIMONIC}

Desde su origen oficioso a mediados del siglo XIX, cuando Thomas Cook funda la considerada primera agencia de viajes europea, el turismo ha mantenido una estrecha y fructífera relación con el patrimonio. No en vano, en muchos casos el turismo ha sido el leiv motiv para salvaguardar obras de interés. Es más, cabe afirmar que las intervenciones en edificios y centros patrimoniales se hacen pensando [casi] exclusivamente en el turismo, como la proyectada reforma de los accesos de La Alhambra de Álvaro Siza, la reforma urbana de Santiago de Compostela promovida por Xerado Estévez y así un sinfín de ejemplos. Asunto de otra índole es la valoración que de estas intervenciones y su sostenibilidad nos merezcan, pues no son pocos los casos en que grandes inversiones en entornos patrimoniales han terminado endeudando más que beneficiando a sus promotores.

Ahora bien, aunque la relación entre turismo y patrimonio ha permanecido a lo largo del tiempo, su formulación ha cambiado en la misma medida en que el concepto de patrimonio ha ido ampliando su significado. Al principio fue el culto al monumento; luego la idea de lo patrimonial incorporaría el entorno de la obra monumental, más tarde incluiría a edificios y conjuntos singulares, hasta llegar a considerar no sólo manifestaciones materiales sino también la herencia cultural intangible. En paralelo e influenciándose mutuamente el "turismo cultural", sin renegar del monumento, fue interesándose por todo tipo de manifestaciones sociales singulares. Las sucesivas Cartas de ICOMOS y de la Lista del Patrimonio Mundial de la UNESCO, por un lado, y la oferta turística, por otro, dan buena cuenta de la riqueza actual del concepto de patrimonio. Esto ha tenido como efecto positivo el reconocimiento de muchos fenómenos culturales tradicionalmente minusvalorados; y como efecto negativo que en esta apertura se ha llegado a exaltar manifestaciones culturales poco significativas, recrear algunas anacrónicas o, incluso, inventar nuevos patrimonios. Se hacen antigüedades a pedido, rezaba hace años el cartel de una tienda de Morelia, México (Goycoolea, 2013).

En esta nueva mirada del patrimonio y del turismo a él asociado, se inscribe un proyecto de recuperación del patrimonio vernáculo que tuve posibilidad de realizar hace unos años en el antiguo Señorío de Molina en la provincia de Guadalajara, España. Esta zona, que comparte parte de su territorio con el Parque Natural del Alto Tajo, experimenta desde fines del siglo pasado una imparable despoblación debida, entre otras razones, a la escasa o nula rentabilidad de las explotaciones agrícolas y ganaderas tradicionales. Como es habitual, con el despoblamiento llegó el abandono de las arquitecturas asociadas a las labores tradicionales. Nuestra tarea consistió en catalogar, visibilizar e intentar dar un uso turístico a estas edificaciones (Núñez, 2012).

No es intención de este artículo mostrar las edificaciones estudiadas ni el trabajo realizado, pero sí utilizarlo como elemento de reflexión sobre el papel del turismo como instrumento de salvaguarda de un tipo de patrimonio, el vernáculo, a los que los estudios académicos y la oferta turística tradicional han prestado poca atención.

En este sentido, es pertinente recalcar que fue la posibilidad de potenciar la economía de la zona a través del turismo lo que permitió convencer a las autoridades del Parque Natural del Alto Tajo para que se preocupasen por un patrimonio abandonado y por el que no habían mostrado mayor interés. Más en concreto, utilizamos los datos de crecimiento del turismo rural como argumento para sacar adelante nuestro proyecto de difusión y salvaguardar el patrimonio vernáculo de la zona.

Lo datos apoyaban nuestra propuesta. Hasta hace unas décadas España era un destino centrado en el turismo de sol y playa -en todas sus expresiones, desde las costas más económicas y masificadas a las exclusivas urbanizaciones de los centros de golf-y en un turismo cultural minoritario anclado en los centros históricos. Hoy, aunque estas tipologías continúan siendo las predominantes, se han ido sumando nuevas modalidades turísticas que han llevado a los turistas, con todo lo que ello implica, a lugares donde el turismo tradicional nunca habría considerado destinos explotables. Entre estas nuevas tipologías destaca, como apuntábamos, el turismo rural.

\section{TURISMO RURAL}

Desde la perspectiva de nuestro tema, hay tres aspectos del turismo rural que nos interesa destacar:

\section{a. Contexto}

Desde una perspectiva general, cabe entenderlo como otra consecuencia de la transformación del turismo en una industria global caracterizada por tres factores interdependientes: Generalización de la oferta por la disminución de los costes del transporte y las trabas aduaneras, la consideración del viaje como símbolo de estatus en las nuevas clases medias de los países emergentes y la ampliación de la oferta turística a todos los segmentos económicos, al punto de que "turistear" ha dejado de considerarse un consumo de orden superior (Esteban, 2004); Diversificación de la oferta, tanto porque los destinos tradicionales comenzaron a superar su capacidad de carga como por las diferencias culturales y aspiraciones de los nuevos viajeros. Si hasta hace pocas décadas la industria turística se dividía en dos grandes grupos -el turista cultural que viajaba para conocer y el turista de ocio que iba a relajarse y descansar-, la oferta actual es enorme en destinos y tipos de viajes. (OSE, 2010); Especialización de la oferta, como consecuencia lógica de lo anterior, pues "ser especial" es una, si no la única, manera de competir en una industria con cada vez más actores competitivos. Sólo quien ofrece algo diferente logra posicionarse en el imaginario de los viajeros para atender demandas cada vez más específicas.

Este cambio en los hábitos de consumo del ocio y, por tanto, en lo que el turismo está demandando y ofertando -con independencia de qué fue antes y qué después- ha sido el elemento imprescindible para entender la aparición y desarrollo del turismo rural. Una modalidad de turismo desarrollada en el entorno europeo, que ha ido extendiéndose sin pausa a nivel mundial.

\section{b. Definición}

El Ministerio de Comercio y Turismo de España (2007) definió el turismo rural como una oferta de actividades recreativas, alojamiento y servicios afines, situada en el medio rural, dirigida principalmente a los habitantes de las ciudades que buscan unas vacaciones en el campo, en contacto con la naturaleza y con la gente local. Pero, en realidad, la demanda no es sólo recreativa. Existen diversas motivaciones ligadas con el conocimiento de culturas autóctonas, la mejora de la calidad de vida y el encuentro con valores tradicionales rurales, el disfrute de paisajes naturales y culturales y la arquitectura vernácula y su entorno, entre otras razones que justifican el desplazamiento de visitantes hacia zonas rurales. 

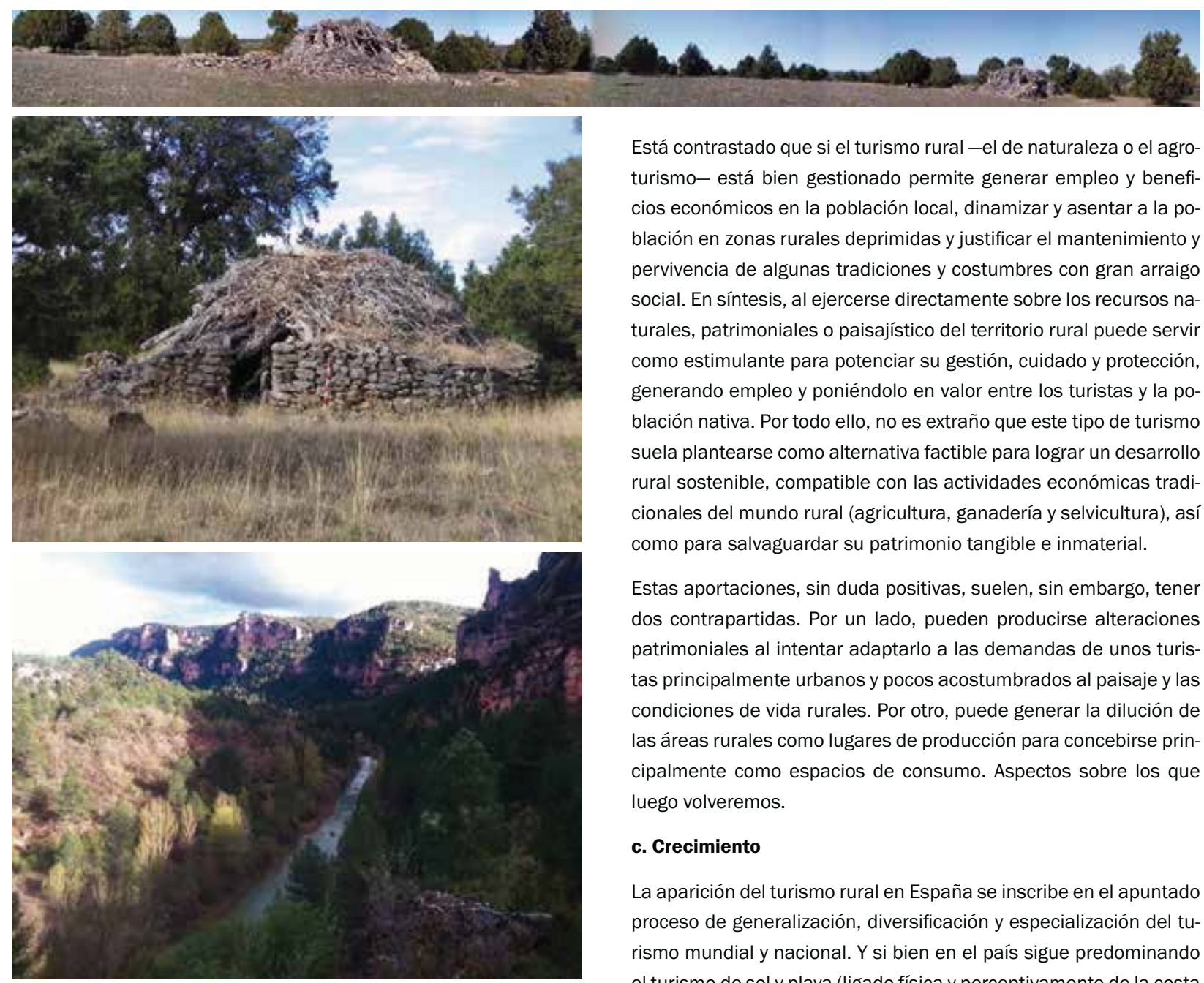

Está contrastado que si el turismo rural -el de naturaleza o el agroturismo- está bien gestionado permite generar empleo y beneficios económicos en la población local, dinamizar y asentar a la población en zonas rurales deprimidas y justificar el mantenimiento y pervivencia de algunas tradiciones y costumbres con gran arraigo social. En síntesis, al ejercerse directamente sobre los recursos naturales, patrimoniales o paisajístico del territorio rural puede servir como estimulante para potenciar su gestión, cuidado y protección, generando empleo y poniéndolo en valor entre los turistas y la población nativa. Por todo ello, no es extraño que este tipo de turismo suela plantearse como alternativa factible para lograr un desarrollo rural sostenible, compatible con las actividades económicas tradicionales del mundo rural (agricultura, ganadería y selvicultura), así como para salvaguardar su patrimonio tangible e inmaterial.

Estas aportaciones, sin duda positivas, suelen, sin embargo, tener dos contrapartidas. Por un lado, pueden producirse alteraciones patrimoniales al intentar adaptarlo a las demandas de unos turistas principalmente urbanos y pocos acostumbrados al paisaje y las condiciones de vida rurales. Por otro, puede generar la dilución de las áreas rurales como lugares de producción para concebirse principalmente como espacios de consumo. Aspectos sobre los que luego volveremos.

\section{c. Crecimiento}

La aparición del turismo rural en España se inscribe en el apuntado proceso de generalización, diversificación y especialización del turismo mundial y nacional. Y si bien en el país sigue predominando el turismo de sol y playa (ligado física y perceptivamente de la costa y sus espacios litorales con manifestaciones ambientales, urbanísticas y económicas específicas) y, en menor medida, en el turismo cultural (ligado a centros urbanos o entornos rurales con "obras de arte", como monasterios, poblados, ermitas, etc.), las cifras muestran que ya no es algo marginal. Desde una perspectiva sociológica las motivaciones del "urbanita", del habitante de la gran ciudad, para demandar este tipo de viajes son tan diversas como personales, aunque cabe destacar la búsqueda de lugares donde minorar el nivel de estrés urbano, el uso y disfrute de la naturaleza, el conocimiento de las culturas tradicionales y el disfrutar de un tiempo de descanso con otro ritmo.

Resulta interesante recalcar el crecimiento y generalización del turismo rural en España, pues al ser el país una de las potencias mundiales de la industria turística debe interpretarse como reflejo de una tendencia que se generalizará (OMT, 2010).

\section{PATRIMONIO VERNÁCULO}

Las edificaciones estudiadas en el Señorío de Molina, como otras asimilables, son, ante todo, "arquitectura sin arquitectos". Edificaciones surgidas de "manera espontánea”, en cuanto están construidas sin proyecto previo, adecuándose a la tradición constructiva y a los materiales de la zona, así como a unas necesidades mínimas reconocidas. (Alonso, Sanz y Sanz, 2007) Su autoría suele ser anónima; como anónima es también la transmisión de las tipologías, los métodos constructivos de alto contenido artesanal, al ridas para construirlas de generación en generación. Con el paso 
del tiempo, se van consolidando tipos y métodos gracias a su repetición, adaptación y utilidad para la vida y el trabajo de quienes las habitan. En nuestro caso, las obras estudiadas fueron de dos tipos: los pajares -o espacios destinados al acopio de cereal dispuestos alrededor de la era de muros de piedra seca y cubierta de teja- y los chozones -o refugios temporales de ganado construidos con muros de piedra seca y estructura y cubierta de barda ${ }^{1}$ (Núñez, 2005). A pesar de su singularidad y valor - pues tienen características particulares únicas frente a otros pajares y majadas o edificaciones ganaderas del resto de la península ibérica-son obras escasamente protegidas frente a las diversas intervenciones que puedan alterar su riqueza arquitectónica en aras de un beneficio económico o simbólico. Especialmente los chozones de barda que, además, podrían incorporarse al catálogo de arquitecturas ganaderas singulares a nivel ibérico (Figura 1. a, b y c).

Probablemente una de las muestras más clara del poco interés disciplinar que existe por este tipo de arquitectura sean las diversas denominaciones que tienen. No me refiero a las denominaciones dadas en cada lugar, que son bien conocidas, sino en cuanto género y/o tipos arquitectónico. Recordemos, por ejemplo, nombres como arquitectura autóctona (la que ha nacido o se ha originado en el mismo lugar donde se encuentra), arquitectura popular (la perteneciente o relativa a un pueblo), arquitectura tradicional (lo que sigue las ideas, normas o costumbres del pasado), etc. Siguiendo a J. Trillerías (2010), consideramos que el término arquitectura vernácula (la doméstica, nativa, de nuestra casa o país) engloba a las demás definiciones y recomendamos su uso.

Uno de los aspectos más interesantes del patrimonio vernáculo es la dificultad que existe para estudiarlo como objeto aislado del contexto que contribuye a configurar, pues sólo en él esta arquitectura tiene su razón de ser. Por ello entendemos que la etnografía o ciencia que estudia las causas y razones de las costumbres y tradiciones de los pueblos (RAE, 2014), ofrece la perspectiva adecuada para entender, difundir y salvaguardarlo.

En este sentido, es interesante observar que la Ley de Patrimonio Histórico española (Ley 16/1985, de 25 de junio) incluye la arquitectura vernácula dentro del Patrimonio Etnográfico, entendido como los bienes muebles e inmuebles y los conocimientos y actividades que son o han sido expresión relevante de la cultura tradicional del pueblo español en sus aspectos materiales, sociales o espirituales (Art. 46). Más en concreto, la Ley define los bienes inmuebles de carácter etnográfico como aquellas edificaciones e instalaciones cuyo modelo constitutivo sea expresión de conocimientos adquiridos, arraigados y trasmitidos según costumbre y cuya factura se acomode, en su conjunto parcialmente, a una clase, tipo o forma arquitectónicos utilizados tradicionalmente por las comunidades o grupos humanos (Art. 47). Incluso amplía el campo de definición más allá del bien inmueble o del hecho edificatorio, incluyéndolo en el concepto de sitio histórico: lugar o paraje natural vinculado a acontecimientos o recuerdos del pasado, a tradiciones populares, creaciones culturales o de la naturaleza y a obras del hombre que posean valor histórico, etnológico, paleontológico o antropológico (Art. 15).

A modo de recapitulación, la Ley española caracteriza al patrimonio vernáculo desde cuatro premisas:

a. Ámbito cultural y económico, al definirla como aquella realizada por clases populares - por oposición a las clases cultas y económicamente pudientes. b. Localización, al definirla como aquella situada en ámbitos rurales o en el campo -en vez de ámbitos urbanos.

c. Morfología, al unificarlas en unas características comunes formales y constructivas según un tipo repetible -opuesta a la arquitectura singular de creación individual.

d. Proceso de proyecto y construcción, al definirla como aquella arquitectura transmitida de forma tradicional en la comunidad mediante gremios u oficios -en vez de enseñanzas regladas. Aplicando estos criterios al estudio de la arquitectura vernácula, se definirían cuatro criterios para caracterizarla: cultural o socioeconómico, geográfico, morfológico y arquitectónico o constructivo.

Pero, con independencia del aspecto que nos interese estudiar, cabe recalcar que la situación general del patrimonio vernáculo español no es alentadora. Salvo excepciones, está siendo víctima de abandono, expolios, demoliciones y/o intervenciones que las alteran sustancialmente. Como apuntábamos, hay una falta de mantenimiento provocado por la fuerte migración del campo a la cuidad y el envejecimiento de la población rural, pero también por la ausencia de una mano de obra cualificada y conocedora de las técnicas tradicionales capaz de cuidarlo. A lo cual hay que sumar un gran desconocimiento social y disciplinar del valor de este patrimonio -como muestra el hecho de que son edificaciones a las que apenas se presta atención en la docencia actual de las Escuelas de arquitectura y asimilables.

Sin embargo, frente a esta triste realidad académica, el turismo rural se presenta como una posibilidad real para lograr su mantenimiento o incluso, recuperación. Pero no cualquier turismo, sino uno que demande estos paisajes culturales, respetándolos y encontrando oportunidades que revitalicen tanto social como económicamente estas poblaciones.

\section{EL TURISMO RURAL Y PATRIMONIO VERNÁCULO}

Aceptar la necesidad de incluir el patrimonio vernáculo en una visión etnográfica más amplia, obliga a abordar su posible recuperación y explotación turística desde una perspectiva estructural y sobre todo ecológica, social y económicamente sostenible. Objetivo en el que la legislación española vuelve a darnos pistas sobre cómo intervenir, pues la Ley 45/2007 sobre el Desarrollo Sostenible del Medio Rural establece las bases de la ordenación general de la actividad económica en dicho medio.

De esta norma, tres de sus artículos inciden directamente en la protección y recuperación del patrimonio vernáculo:

Art. 2. Objetivos. El Objetivo C. habla de conservar y recuperar el patrimonio y los recursos naturales y culturales del medio rural a través de actuaciones públicas y privadas que permitan su utilización compatible con un desarrollo sostenible. Y el Objetivo E. habla de lograr un alto nivel de calidad ambiental en el medio rural previniendo el deterioro del patrimonio natural, del paisaje y la biodiversidad o facilitando su recuperación, mediante: la ordenación integrada del uso del territorio para diferentes actividades, la mejora de la planificación y gestión de los recursos naturales y la reducción de la contaminación en zonas rurales.

Art. 29. Cultura. Con el objetivo de permitir el mantenimiento de una oferta cultural estable y próxima en el medio rural, se deben establecer programas que permitan: a. Crear redes de espacios culturales que, reutilizando el patrimonio arquitectónico existente, garanticen la infraestructura para su desarrollo con la mayor poli- 
valencia posible, la dimensión adecuada para garantizar su sostenimiento y su accesibilidad. b. Impulsar planes de actividades culturales por zona rural, favoreciendo la participación y la iniciativa de todo tipo de entidades privadas y e. Proteger el patrimonio histórico - artístico ubicado en los municipios rurales y fomentar su mantenimiento y restauración adecuados.

Art. 33. Urbanismo y vivienda. El punto $C$ habla de fomentar la reutilización de las viviendas y edificaciones existentes, la preservación de la arquitectura rural tradicional y la declaración de áreas de rehabilitación de los municipios rurales con el objetivo de recuperar y conservar el patrimonio paisajístico y arquitectónico rural.

Aunque no lo diga de manera explícita, en el espíritu de la Ley subyace la idea de fomentar el turismo rural para lograr el un desarrollo compatible con la salvaguarda del patrimonio vernáculo. Y, en términos generales, así está ocurriendo. La presencia de turistas urbanos en zonas rurales está originando una creciente demanda de "bienes de alto consumo" como elementos clave para la propia existencia del turismo rural, apareciendo nuevas oportunidades de desarrollo en sectores vinculados a los servicios ambientales, la hostelería, la gastronomía, el ocio activo, etc.

Según el Manual del Planificador del Turismo Rural (MECT, 1994) los beneficios de estas actividades en el ámbito rural son varios y de distinta naturaleza: a. Crecimiento y rejuvenecimiento demográfico: las nuevas actividades, necesitadas de mano de obra en edad laboral provocan la permanencia de la población local e incluso la llegada de emigrantes. b. Creación de empleos directos e indirectos. c. Financiación de infraestructuras por el aumento de ingresos y de la actividad económica, generando un aumento de los ingresos fiscales de los municipios locales y una oferta de calidad que atraerá a más turistas, más ingresos, etc. d. Mejora de la calidad de vida de los habitantes, tanto desde el punto de vista económico (empleo, ingresos) como social (mejora de servicios, más oportunidades de relación y contacto con nuevas experiencias y formas de vida). e. Refuerzo del sentimiento de identidad y modernización de la sociedad al revalorizar las zonas receptoras y dar a sus habitantes confianza en sus propias posibilidades gracias al sentimiento de cohesión interna entre la población autóctona y los turistas. En síntesis, la administración entiende el turismo, inyecta nuevos aires en el seno de la población y añade a los valores tradicionales otros más modernos y estimulantes.

Con esta perspectiva, a principios de la década de 1990 la Unión Europea lanzó el primer programa de ayudas económicas para la revitalización y desarrollo local LEADER -acrónimo en francés de Liaisons entre activités de Developement de L'Economie Rural (Relaciones entre actividades de desarrollo de la economía rural). Su puesta en marcha marca el inicio de una nueva concepción de la política de desarrollo rural basada en un enfoque territorial, integrado y participativo que se mantiene.

Estas ayudas tuvieron los resultados esperados. Sembraron de alojamientos rurales los países europeos, promoviendo una movilidad de fin de semana a destinos cercanos que pudiese ofrecer una alternativa sostenible y atractiva al turismo tal y como se había entendido hasta entonces. Y, de paso, que contribuyese a la rehabilitación del patrimonio vernáculo.

\section{CRITERIOS DE INTERVENCIÓN EN}

\section{EL PATRIMONIO VERNÁCULO}

En la recuperación del patrimonio vernáculo, como en los demás patrimonios, no existen criterios unívocos de intervención. En realidad, existen distintas líneas para acometer su salvaguarda o rehabilitación según sean los intereses sociales, económicos y/o turísticos marcados. Lo que sí es común en el ámbito europeo, es el control administrativo de estas intervenciones, pues en todos los casos para poder intervenir sobre el patrimonio vernáculo es necesaria la redacción de un proyecto de ejecución, una dirección facultativa y licencias como cualquier obra de rehabilitación del patrimonio "culto". Visto con perspectiva histórica, no dejan de ser contradictorias todas estas gestiones técnicas y administrativas para intervenir sobre patrimonios realizado por autores anónimos y sin documentos técnicos ni cálculos previos de ningún tipo.

En todo caso y bajo cualquier criterio, entendemos que hay una serie de aspectos que deberían guiar cualquier intervención sobre el patrimonio vernáculo:

a. Buscar la coherencia de las soluciones técnicas propuestas en la intervención y su sostenibilidad con su génesis arquitectónicas y sentido social. Nos referimos a recordar siempre que la ejecución material del patrimonio vernáculo se llevó a cabo mediante materiales y mano de obra del lugar. Por eso, nos resulta impensable intervenir en un edificio de uso agrícola, por ejemplo, por alguien que desconozca el oficio e ignore las necesidades y la adecuación de los materiales a su uso. De ahí que contratar para estas rehabilitaciones a mano de obra no especializada, desconocedora del medio, sin habilidades adecuadas y con soluciones técnicas excesivamente complejas, parece un contrasentido técnico y arquitectónico.

b. Otro tema a considerar en el caso de las arquitecturas vernáculas vinculadas a actividades económicas concretas, es que el tiempo de ejecución fue muy corto. Debían construirse en un periodo determinado que permitiese comenzar a sacar rendimiento del oficio cuanto antes. De ello dependía la economía familiar sin posibilidad de otro medio de vida, por lo que todos colaboraban en la construcción. Una posibilidad de autoconstrucción apoyada en el uso de procesos de diseño y construcción elementales transmitidos por la experiencia directa.

c. No hay que olvidar tampoco la estabilidad formal de estas construcciones. A nivel nacional, la exhaustiva catalogación del patrimonio vernáculo llevada a cabo por la Administración Pública, Universidades y Centros de Investigación nos muestran que, una vez establecido el tipo, éste se mantiene casi sin modificaciones formales ni cambios en los sistemas constructivos. Sólo una modificación significativa de las condiciones socioeconómicas y/o ambientales de una región conducía a la modificación del tipo.

d. Una última consideración común para cualquier intervención es la íntima relación que tiene el patrimonio vernáculo con el entorno, al punto de ser parte de un paisaje natural / cultural del que no se puede disociar. Por eso, la descontextualización de este patrimonio suele llevar a anacronismos absurdos.

\section{ESTRATEGIAS DE INTERVENCIÓN}

El análisis de las obras realizadas en las últimas décadas sobre el patrimonio vernáculo español considerando, por un lado, la legislación vigente y, por otro, el turismo -en cuanto actividad econó- 
mica que ha permitido o justificado estas actuaciones-, permite identificar las cinco líneas de intervención que a continuación se resumen. Antes, cabe apuntar que no se trata de estrategias abstractas, al ser cada una un resumen de ejemplos concretos.

a. Reconstrucción museística, cuando lo prioritario es "reconstruir" la obra a su estado original con el fin de convertirlas en objetos de exhibición, en testimonios inmaculados de construcciones o conjuntos paisajísticos singulares. Los promotores de estas intervenciones -que obligan en su afán de autenticidad a utilizar las técnicas constructivas arraigadas en la comarca donde se ubicansuelen recalcar la dificultades que tuvieron para encontrar operarios especializados que estén vivos o en edad laboral. Una solución positiva a esta carencia, por los diversos beneficios que trae, son las escuelas - taller, donde a través de la rehabilitación de un edificio específico se enseñan oficios que tienden a su desaparición.

Ejemplo paradigmático de esta estrategia de recuperación del patrimonio vernáculo serían los Teitos de Somiedo en Asturias. Una intervención que permite ver con fidelidad cómo eran estas construcciones, al punto de que podemos pensar que la arquitectura y el paisaje han quedado congelados en el tiempo, aunque sin los pastores de ganado vacuno que los justificaban. Son hitos arquitectónicos, paradigmas de oficios pasados que, respetuosos con la técnica y la herencia de sus antecesores, muestran -no sin nostalgia- una vida que fue y que, probablemente, no volverá. (Menéndez, 2008). La recuperación y gestión posterior del conjunto fue una promoción pública, con fuerte inversión de la administración local, con el fin de promover el turismo cultural y etnológico. Objetivo que se ha cumplido con creces, pues es uno de los paisajes etnográficos más visitados en el Principado de Asturias (Figura 2).

b. Reconstrucción o recreación para uso turístico. Esta línea se diferencia de la anterior en que su fin no es la exhibición sino la utilización efectiva del patrimonio intervenido. La idea de proponer nuevos usos para el patrimonio es, sin duda, una de las más empleadas para su salvaguarda y sostenibilidad. Los ejemplos de este tipo de intervenciones en el patrimonio arquitectónico urbano o de edificios singulares son muchos y, en términos generales, los resultados positivos. Sin embargo, cuando esta línea de actuación se traslada al ámbito del patrimonio vernáculo la situación suele invertirse acumulándose ejemplos negativos, por distintas razones. Si bien, entre ellas destacaría tres: Por un lado, la urgencia de captar subvenciones para el turismo rural ha llevado a muchas intervenciones aceleradas sin ninguna reflexión teórica e, incluso, sin estudios previos por personal cualificado. Por otro lado, los turistas no dejan de ser urbanitas y exigen diversos servicios difícilmente compatibles con el patrimonio vernáculo. Por último, están los imaginarios de lo que se entiende por turismo rural, imágenes "con encanto" eminentemente bucólicas, que condicionan las intervenciones.

Resultado de estos factores es que muchas recuperaciones turísticas del patrimonio vernáculo suelen terminar en parodias arquitectónicas. Intervenciones donde prima la búsqueda de la rentabilidad económica ofreciéndole al turista espacios pintorescos, productos de un imaginario colectivo y romántico de la vida en el campo aunque completamente desligados al entorno y a su uso original. Lo cual no significa que estos parajes rurales artificiales atraigan a un nutrido número de visitantes (Figura 3. a y b).

c. Conservación etnoarqueológica, basada en una disciplina cuyo objetivo es el estudio de las comunidades preindustriales contem-
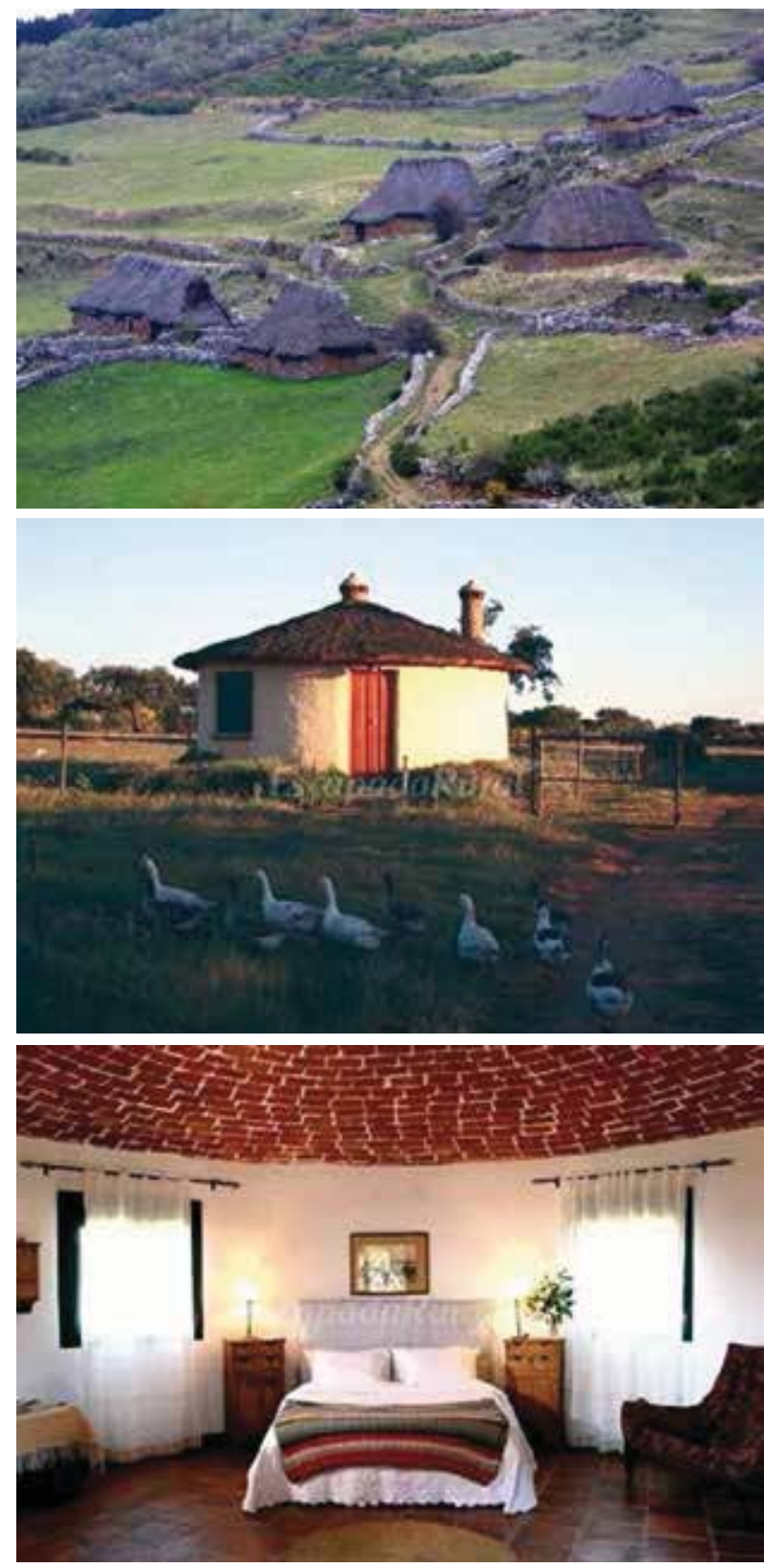

$>$ Figura 2. Paisaje de Teitos. Somiedo, Asturias, España. Fuente: Menén dez, 2008.

Figura 3. Chozo "rural". Valle del Mira, Badajoz. Fuente: www.toprural. com, consulta 02.04.2015. 

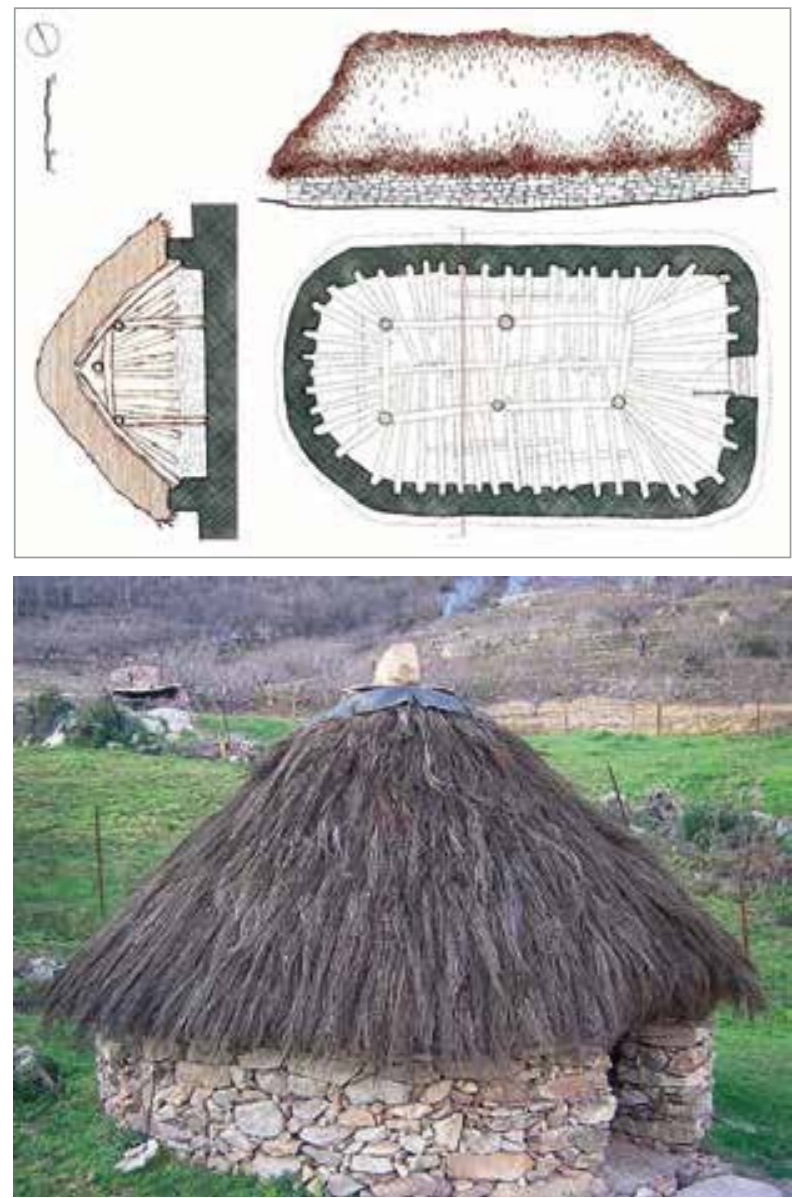

Figura 4. Chozón. Ablanque, Guadalajara, España. Elaboración propia.

$>$ Figura 5. Chozo de cabrero. El Torno, Cáceres. Fuente: Flores, 1992. poráneas, con una visión eminentemente arqueológica. Se diferencia de la etnografía y la antropología por tener un enfoque, métodos y propósitos más ligados a la arqueología, considerando los restos arquitectónicos como espacios generados por una forma de vida determinada; como materializaciones de una sociedad y una expresión vivencial concreta. Según Schiffer (1976:IX), los trabajos etnoarqueológicos tienen un objetivo transversal con las demás disciplinas de las Ciencias sociales en cuanto intentan establecer las relaciones entre la cultura material y el comportamiento en las sociedades humanas. Así entendida, comparte en su concepción y desarrollo las experiencias obtenidas de la arqueología y la antropología, pero basándose en los aportes de los arqueólogos sobre la cultura material de las sociedades pre modernas vivas (González Ruibal, 2003). La etnoarqueología propicia que se reavive la imaginación arqueológico-interpretativa, ofrece estímulos y referencias que sirven para ir construyendo un marco de comprensión general de las culturas humanas; y amplían el abanico de hilos interpretativos disponibles para los arqueólogos en sus reconstrucciones narrativas del pasado (González Ruibal, 2001 y 2003).

Esta estrategia de intervención no focaliza la recuperación o la investigación de la edificación y su estado de conservación en el objeto en sí -en la obra específica- sino en el conjunto global de la cultura concreta en que se insertan. Gracias a esta disciplina, puede conocerse el contexto y la función de conjuntos vernáculos, como por ejemplo, el paisaje generado por la ganadería extensiva en el Señorío de Molina de Alto Tajo: majadas y salegares ubicados dehesas cercadas nos hablan de ganadería ovina estante en monte público (Figura 4).

d. Rehabilitación para su uso original. Esta línea de intervención es la antagónica de la primera y una expresión extrema de la anterior. En términos cuantitativos es una estrategia minoritaria pero, en términos teóricos, es la que más se acerca al concepto de rehabilitación. Como el propio término indica, toda rehabilitación exigiría una continuidad en el uso específico de la construcción: agropecuario, horno, refugio temporal, etc. Y, para ello, dicha actividad debería mantenerse en los municipios, o al menos, recuperarse. Como decía, esta situación apenas se está dando en nuestro país. Las continuas migraciones del campo a la ciudad y las oportunidades económicas que ofrecen las urbes imposibilitan esta cuestión.

En casos muy concretos y bastante escasos, son los propios dueños de este patrimonio, los que están manteniendo tanto su estado como el uso original aún sin apenas contar con subvenciones públicas para ello, como sucede en el valle del Torno, Cáceres, con la propuesta de la Junta de Extremadura de recuperar el sistema ganadero extensivo ovino (Figura 5).

e. Restauración integral. En esta denominación integramos aquellas iniciativas que aúnan el carácter turístico y el patrimonial donde aunar el paisaje cultural propio de una población con el componente etnológico. Al menos en España, la mayoría de las intervenciones de este tipo están enmarcadas en paisajes naturales protegidos o simplemente de interés. Los objetivos básicos de estas intervenciones son: a. dinamizar económica y socialmente a las poblaciones mediante la restauración de edificaciones con constructivas autóctonas y materiales del lugar; b. ofrecer un turismo rural mediante itinerarios donde unir naturaleza y arquitectura; c. dar a conocer una cultura desaparecida de la que el visitante ha podido formar parte, aun corriendo el riesgo de congelar el dinamismo que mantiene en pie a este patrimonio. 


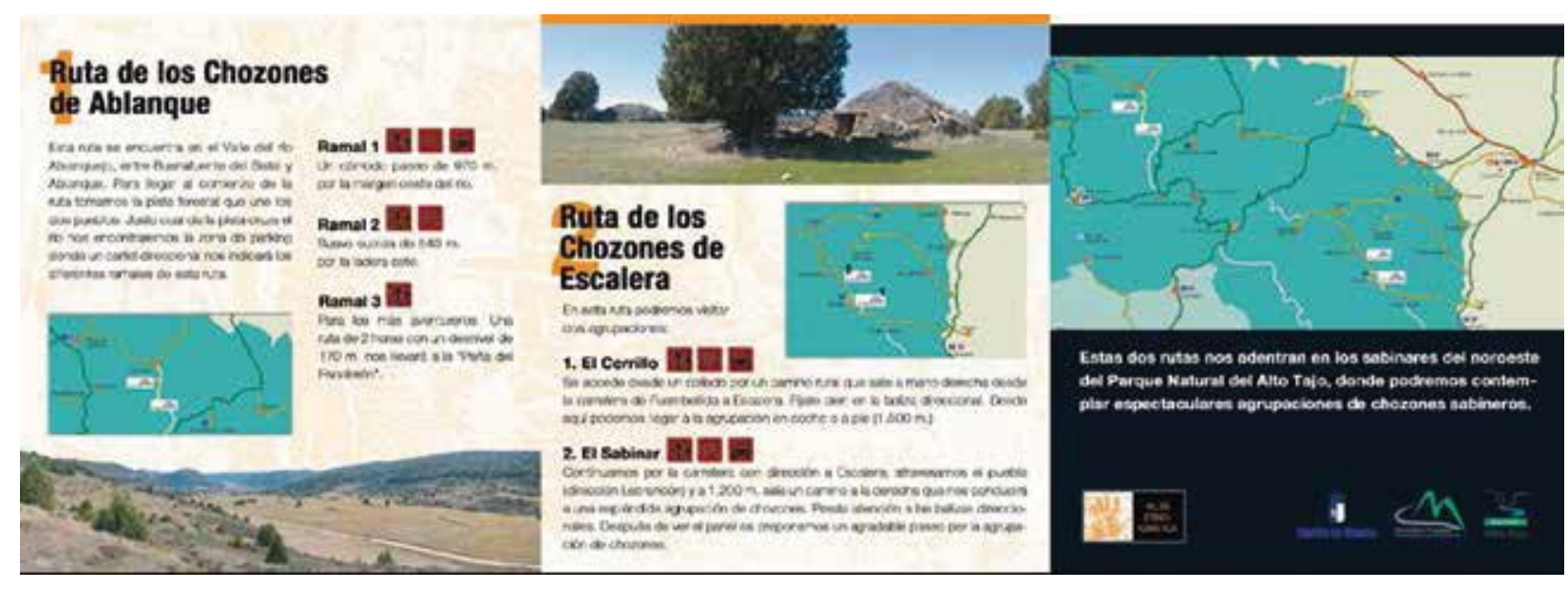

Ejemplo de este tipo de intervención son las Rutas Etnográficas del Parque Natural del Alto Tajo (Guadalajara, España). En ellas se propone al turista una serie de recorridos por distintos municipios de la zona donde podrá encontrar excelentes edificaciones destinadas al uso agropecuario denominados chozones, que servían para cobijar al ganado ovino. La excepcionalidad de este caso estriba en el buen estado de conservación de estas construcciones (la actividad entró en declive a finales de la década de 1970) y en la apuesta por parte de la administración pública en revitalización la zona, respetando el medioambiente, el uso original de dichas construcciones y alentando un incipiente grupo de artesanos albañiles que vayan poco a poco manteniéndolos (Figura 6).

\section{A MODO DE CONCLUSIÓN}

Comenzamos estas notas haciéndonos una pregunta: ¿Es posible que el turismo permita una salvaguarda sostenible del patrimonio vernáculo?

Por lo que hemos investigado y expuesto, la respuesta no es única. Hemos intentado averiguar qué se entiende por patrimonio vernáculo y qué por un turismo que haga sostenibles las intervenciones en estas edificaciones. Además, hemos comprobado que, al menos en el caso español, existen leyes que otorgan valor al patrimonio etnológico o vernáculo y que regulan el desarrollo sostenible del medio rural. Por último, nos hemos centrado en las estrategias que se están desarrollando para intervenir en el patrimonio vernáculo.

Todo este trabajo, nos permite aventurar una serie de conclusiones o consideraciones sobre el tema tratado:

- La pérdida del patrimonio vernáculo sería irreparable para la cultura nacional. Ahora bien, también sabemos que si no se les otorga de un valor de uso añadido, su recuperación es también baladí.

- Una de las estrategias para justificar su mantenimiento o rehabilitación sería la de considerar el patrimonio vernáculo como foco de atracción de un turismo respetuoso que busca, en entornos naturales, otro tipo de ocio y de conocimiento más vinculado con lo rural, considerado en ocasiones, como genuino.

- Además, la Ley de Desarrollo Sostenible del Medio Rural integra en el patrimonio vernáculo en la industria turística siempre bajo una adecuada gestión de las actuaciones con el fin de repercutir positivamente sobre: las condiciones sociales (económicas y culturales) de la población local, el medio ambiente y recursos naturales del lugar. 


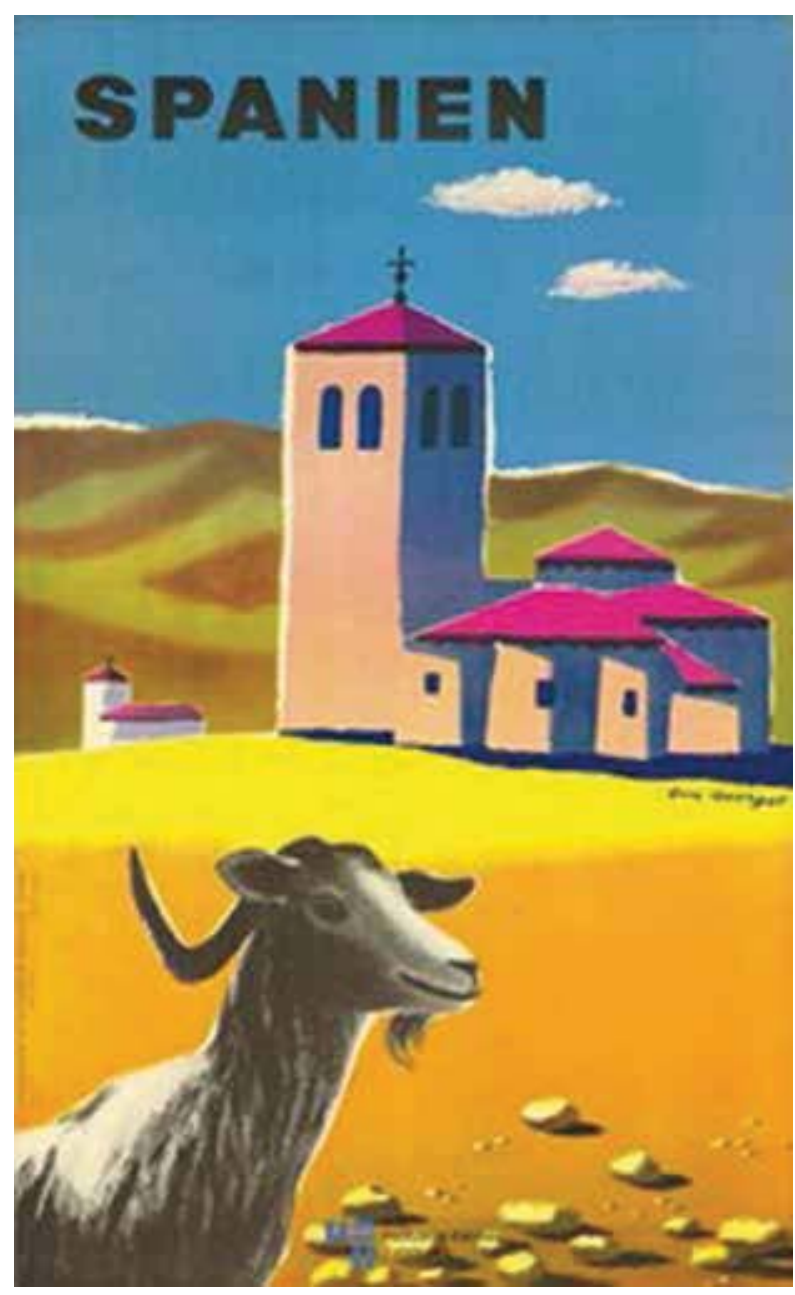

- No todo el turismo ni toda intervención patrimonial es sostenible. Tal y como se ha venido desarrollando la industria turística española -con una gran presión sobre ecosistemas interiores (actividades en la naturaleza) y costeros (segundas residencias en el litoral), el consumo de agua, las emisiones, la generación de residuos, etc.hace necesario desarrollar otros modelos de utilización y gestión de los recursos turísticos sino queremos terminar destruyéndolos. Una alternativa viable es potenciar un turismo interior hacia zonas de alto valor natural y cultural, espacios naturales y rurales con una implicación directa en las zonas en las que se desarrolle tanto a nivel económico, social, como ambiental y cultural.

- Frente a esta situación también aparecen oportunidades de futuro ligadas a un turismo que contribuya a la sostenibilidad de los ecosistemas. La recuperación integral del paisaje cultural y la arquitectura de estos pueblos visibilizaría una riqueza patrimonial denostada, fortalecería las capacidades de los habitantes, generaría empleo, avalaría su valor patrimonial, además de conservar y honrar la tradición e identidad del lugar. Y, por supuesto, supondría una posibilidad de turismo para un sector de la población cada vez más interesado por la ecología.

- Los fondos europeos y nacionales para la intervención en este tipo de patrimonio son muy escasos y en caso de darse, priorizan un nuevo uso terciario, productivo que reinvierta directamente en la bolsa turística del lugar sin respetar la memoria colectiva. ¿Acaso no hay otra posibilidad de recuperación que convertir en museos o casas rurales edificaciones ancestrales que no estaban concebidas para cumplir ningún código técnico de la edificación? En cualquier caso, hace falta una seria reflexión sobre la idoneidad de rehabilitar, reconstruir o restaurar el patrimonio vernáculo bajo criterios de sostenibilidad y sustentabilidad, es decir, de permanencia a lo largo del tiempo con el menor coste económico, ambiental y energético y sin engaños culturales sobre su uso y origen.

Las preguntas están abiertas. A lo mejor hay que dejar que estas construcciones decaigan y el caminante las encuentre por sorpresa, las disfrute temporalmente, sepa respetarlas y despierte en él el interés del conocimiento. A lo mejor hay que incentivar la pervivencia de estos oficios tradicionales a través de escuelas taller gestionadas desde las administraciones locales. 0 incluso, aprender de iniciativas europeas, tales como las del Reino Unido llevadas a cabo por John Letts y el estudio arqueobotánico de los tejados de paja antiguos, o los de Italia, con María Rosa Bagnari, directora del Eco museo de la civilización palustre en Rávena.

Sea como fuere, la intervención urge. Aunque sea para que el turista descubra otra forma de apropiación del paisaje natural y se deje atrapar por la belleza (Figura 7).

\section{BIBLIOGRAFÍA}

\section{AA. VV. (2010), "Empleo verde en una economía sostenible", Madrid: Observatorio para la Sostenibilidad en España y Fundación Biodiversidad.}

ALONSO, T.; SANZ, D. y SANZ, E. (2007), "Arquitectura popular en tierra Molina”, Guadalajara: Junta de Comunidades de Castilla la Mancha.

BARRERA, E. y MUÑOZ, R. (2003), "Manual de Turismo Rural para micro, pequeños y medianos empresarios rurales", Buenos Aires: Fondo Internacional de Desarrollo Agrícola. 
CALS, J.; CAPELLA, J. y VAQUÉ, E. (1995), "El turismo en el desarrollo rural de España", Madrid: Ministerio de Agricultura, Pesca y Alimentación.

ESTEBAN, Á. (2004), Modelos de la demanda turística en España: segmentación por países de procedencia, "Las Nuevas formas del Turismo", Vol. 5, pp. 81-101, Colección Mediterráneo Económico.

FLORES DEL MANZANO, F. (1992), "La vida tradicional en el Valle del Jerte", Mérida: Asamblea de Extremadura.

GONZÁLEZ RUIBAL, A. (2001), Etnoarqueología de la vivienda en África subsahariana: Aspectos simbólicos y sociales, en Arqueoweb, 3(2), http://www.ucm.es/info/arqueowe, consulta 06.05.2015.

GONZÁLEZ RUIBAL, A. (2003), "La experiencia del otro. Una introducción a la Etnoarqueología", Madrid: Akal.

GOYCOOLEA PRADO, R. (2013), Imaginarios turísticos y configuración del espacio. México en la Guía Verde, Arkeopáticos, Textos sobre arqueología y patrimonio $\mathrm{N}^{\circ} 2$, p. 23-38, México: Arkiopatías, disponible en: http://arkeopatias. wordpress.com/2013/02/20/revista-textos-arkeopaticosnumero-02-invierno-2013/

MCT - MINISTERIO DE COMERCIO Y TURISMO (2007), "Manual de Turismo Rural para micro, pequeños y medianos empresarios rurales", Gobierno de España.

MECT - MINISTERIO DE ENERGÍA, COMERCIO Y TURISMO (1994), "Manual del Planificador del Turismo Rural", Gobierno de España.

MENÉNDEZ, C. (2008), "Teitos. Cubiertas vegetales de Europa Occidental: de Asturias a Islandia" Oviedo: COAAT del Principado de Asturias.

MIET - MINISTERIO DE INDUSTRIA, ENERGÍA Y TURISMO (2012), "Balance del turismo. Resultados de la actividad turística en España", Madrid.

NÚÑEZ MARTí, P. (2005), Evolución tipológica en las construcciones vernáculas del Parque Natural del Alto Tajo y su zona periférica de Protección (Guadalajara), Actas del I Jornadas de Investigación en Construcción, Madrid: Instituto de Ciencias de la Construcción Eduardo Torroja, CSIC.

NÚÑEZ MARTÍ, P. (2012), Turismo y patrimonio vernáculo: ¿Estrategia de recuperación sustentable?, Actas del $2^{\circ}$ Coloquio Red Internacional de pensamiento crítico sobre globalización y patrimonio construido, Florencia, pp. 543-555.

OBSERVATORIO EUROPEO LEADER (2001), Construir una estrategia de desarrollo territorial con base en la experiencia LEADER. 5 Innovación en el Medio Rural, C. Innovación № 6.

OMT - ORGANIZACIÓN MUNDIAL DEL TURISMO (2010), "Foro Global de Turismo", Andorra.

OSE - FUNDACIÓN BIODIVERSIDAD (2010), “Empleo verde en una economía sostenible", Informe.

SCHIFFER, M. B. (1976), "Behavioral archaeology", New York: Academic Press.

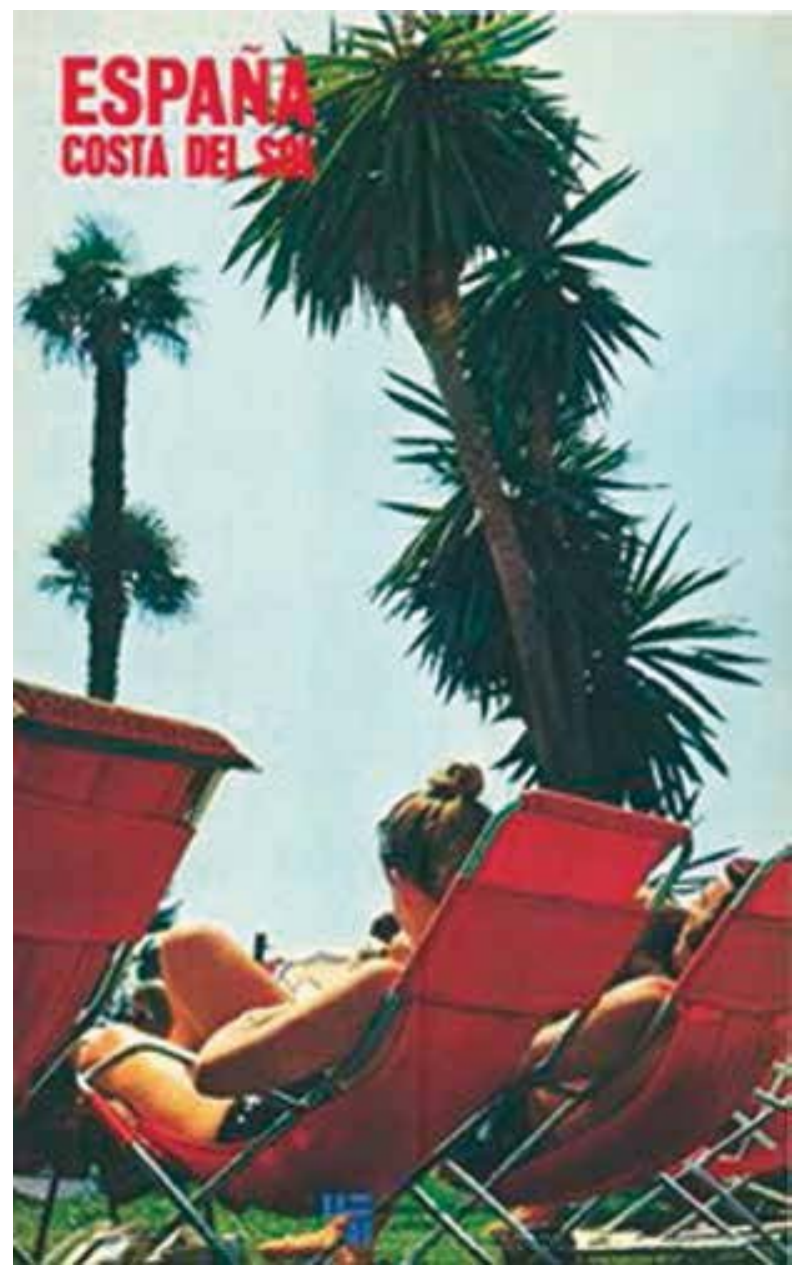


TILLERÍA, J. (2010), La arquitectura sin arquitectos, algunas reflexiones sobre arquitectura vernácula, Revista AUS, disponible en: http://www.redalyc.org/articulo. oa? $\mathrm{id}=281722857004$, consulta: 5.06 .2015 .

\section{NOTAS}

1 Cubierta de sarmientos, paja, espinos o broza, que se pone, asegurada con tierra o piedras, sobre las tapias de los corrales, huertas y heredades, para su resguardo (RAE, edición 2014). En nuestro caso, se trata de las ramas de sabinas y encinas provenientes de la poda de los ejemplares colindantes al chozón, colocadas sin ningún tipo de sujeción ni mortero, simplemente mediante acopio. 